\title{
ТРАНСФОРМАЦИЯ АЗОТА И АКТИВНОСТЬ УРЕАЗЫ ПРИ ИСПОЛЬЗОВАНИИ ГЕРБИЦИДОВ
}

\author{
A.A. Belousov, E.N. Belousova, V.L. Bopp, \\ V.S. Litvinova, T.S. Antonova
}

\section{TRANSFORMATION OF NITROGEN AND UREASE ACTIVITY WHEN USING HERBICIDES}

Белоусов А.А. - канд. биол. наук, доц. каф. почвоведения и агрохимии Красноярского государственного аграрного университета, г. Красноярск.

E-mail: svoboda57130@mail.ru

Белоусова Е.H. - канд. биол. наук, доц. доц. каф. почвоведения и агрохимии Красноярского государственного аграрного университета, г. Красноярск.

E-mail: svobodalist571301858@mail.ru

Бonn В.Л. - канд. биол. наук, доц., проректор по науке Красноярского государственного аграрного университета, г. Красноярск.

E-mail: vl kolesnikova@mail.ru

Литвинова В.С. - канд. С.-х. наук, доц. каф. государственного, муниципального управления и кадровой политики Красноярского государственного аграрного университета, г. Красноярск.

E-mail: tina.litvinova@mail.ru

Антонова T.C. - магистрант каф. почвоведения и агрохимии Красноярского государственного аграрного университета, г. Красноярск.

E-mail: ats2285@mail.ru

Цель исследования - оценить влияние гербицидов на превращение соединений азота, активность уреазы чернозема выщелоченного, а также продуктивность кукурузы в условиях лесостепной зоны Красноярского края. Исследование проводили на черноземе выщелоченном опьтнного стационара Красноярского ГАУ в 2018 г. Схема опыта представлена следующими вариантами (препаратами ффирмы «Байер»): 1. Контроль; 2. «Аденго»; 3. «Майстер КомбиПак»; 4. «Майстер Пауэр». Опыт заложен в трехкратной повторности, размещение делянок систематическое. Предшественник: чистьй пар. Общая площадь опытной делянки составила 500 м². Почвенные образцы отбирали из слоев 0-10 и 10-20 см: до
Belousov A.A. - Cand. Biol. Sci., Assoc. Prof., Chair of Soil Science and Agrochemistry, Krasnoyarsk State Agrarian University, Krasnoyarsk.

E-mail: svoboda57130@mail.ru

Belousova E.N. - Cand. Biol. Sci., Assoc. Prof., Chair of Soil Science and Agrochemistry, Krasnoyarsk State Agrarian University, Krasnoyarsk.

E-mail: svobodalist571301858@mail.ru

Bopp V.L. - Cand. Biol. Sci., Assoc. Prof., ViceRector for Science, Krasnoyarsk State Agrarian University, Krasnoyarsk.

E-mail: vl kolesnikova@mail.ru

Litvinova V.S. - Cand. Agr. Sci., Assoc. Prof., Chair of Public, Municipal Administration and Personnel Policy, Krasnoyarsk State Agrarian University, Krasnoyarsk.

E-mail: tina.litvinova@mail.ru

Antonova T.S. - Magistrate Student, Chair of Soil Science and Agrochemistry Krasnoyarsk State Agrarian University, Krasnoyarsk.

E-mail: ats2285@mail.ru

обработки (фон), а также через 7 и 37 дней после обработки. В эксперименте использовали гибрид кукурузы $F_{1}$ Катерина СВ. В течение вегетационного сезона наблюдали за динамикой азотсодержащих соединений: щелочногидролизуемого и аммиачного азота, а также уреазной активностью почвы. Воздействие испытуемых гербицидов не выявило закономерных изменений в превращениях легкогидролизуемых соединений азота. Обнаружен ингибирующий эфффрект гербицидов "Аденго» и «Майстер Пауэр» на почвенную уреазу. «Майстер КомбиПак» по-иному воздействовал на интенсивность гидролиза мочевины. Снижение активности уреазы сопровождалось достоверным нарастанием содержания аммоний- 
ного азота. Использование гербицидов оказало существенное влияние на формирование зеленой массы, обеспечив повышение продуктивности по отношению к контролю от 21,7 до 66,3 \%. Применение гербицидов оказало значительное влияние на рост растений кукурузы, способствуя повышению морфометрических показателей.

Ключевые слова: кукуруза, гербициды, щелочногидролизуемый азот, аммиачный азот, почвенная уреаза.

The aim of the work was to assess the influence of herbicides on the conversion of nitrogen compounds, the activity of leached Chernozem urease, and the productivity of maize in the forest-steppe zone of Krasnoyarsk Region. The studies were carried out on leached Chernozem of experimental hospital of Krasnoyarsk SAU in 2018. The scheme of the experiment was represented by the following options (Bayer preparations): 1. Control; 2. Adengo; 3. Meister CombiPack; 4. Meister. The experiment was built in triple repetition; the placement of plots was systematic. The predecessor was bare fallow. The total area of the allotment made $500 \mathrm{~m}^{2}$. The soil samples were taken from the layers $0-10$ and 10-20 cm: before treatment (background), and 7 and 37 days after treatment. The experiment used a hybrid of corn of $F_{1}$ "Katerina SV". During growing season the dynamics of nitrogen-containing compounds was observed: alkaline hydrolyzed and ammonium nitrogen, as well as urease activity of the soil. The influence of tested herbicides did not reveal any regular changes in the transformations of easily hydrolyzed nitrogen compounds. Inhibitory effect of herbicides Adengo and Meister Power on soil urease was found. Meister CombiPack differently affected the intensity of urea hydrolysis. The decrease in urease activity was accompanied by a significant increase in the content of ammonium nitrogen. The use of herbicides had a significant impact on the formation of green mass, providing an increase in productivity relative to the control from 21.7 to $66.3 \%$. The use of herbicides has had a significant impact on the growth of maize plants, contributing to an increase in morphometric indicators.
Keywords: corn, herbicides, alkaline hydrolyzable nitrogen, ammonium nitrogen, soil urease.

Введение. В структуре посевных кормовых культур Российской Федерации кукуруза занимает третье место (22,4 \%). Ежегодно в Красноярском крае сельскохозяйственные товаропроизводители увеличивают площадь под кукурузой: в 2014 г. она занимала 16,3 тыс. га, в $2015-18,1$; в 2016 - 21,2; в 2017 - 22,0; в 2018 г. 23,0 тыс. га. Поскольку посевы кукурузы на силос убираются в фразе молочно-восковой и восковой спелости зерна, то их возделывание по зерновой технологии сопровождается мероприятиями по защите культуры, в том числе и от сорных растений [1].

Сбалансированная химизация растениеводства с использованием регуляторов роста и гербицидов позволяет добиться существенного увеличения урожайности. С другой стороны, использование средств защиты растений является экологически рискованным, но, очевидно, почти незаменимым технологическим приемом борьбы с вредными объектами на сельскохозяйственных культурах. Гербициды, являясь сложными химическими соединениями, могут оказывать весьма существенное влияние как на пищевой режим почв, так и на уровень ее биологической активности [2]. В лесостепной зоне Красноярского края агроэкологическая оценка воздействия агрохимикатов на почвенную биоту проводилась недостаточно [3, 4]. Поэтому актуальным является вопрос о необходимости соблюдения экологической безопасности при применении в сельском хозяйстве ядохимикатов, в частности гербицидов.

Цель исследования: изучить влияние гербицидной нагрузки на содержание подвижных форм азота и активность уреазы чернозема выщелоченного под посевами кукурузы.

Объект и методы исследования. Исследование проводили на полевом стационаре УНПК «Борский» Красноярского ГАУ, расположенном на территории Сухобузимского района в пределах Чулымо-Енисейского денудационного плато югозападной окраины Средней Сибири (56²6' с. ш. и $92^{\circ} 54^{\prime}$ в. д.).

Объект исследований - чернозем выщелоченный маломощный среднегумусный тяжело- 
суглинистый иловато-пылеватый на коричневобурых тяжелых суглинках. Почва опытного стационара характеризовалась высоким содержанием гумуса - 9,3 \%, рН близкой к нейтральной $(6,8-6,9)$, высокой поглотительной способностью (ЕКО = 56,5 ммоль/100 г) и насыщенностью основаниями ( $\mathrm{V}=97 \%$ ), повышенным содержанием подвижного фоссфора $\left(\mathrm{P}_{2} \mathrm{O}_{5}=20-22\right.$ мг/100 г) и очень высокой обеспеченностью обменным калием (К $2 \mathrm{O}=25-27$ мг/100 г).

Опыт заложен в трехкратной повторности, размещение делянок систематическое. Общая

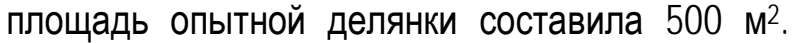
Обработка почвы включала: зяблевую плоскорезную основную обработку на глубину $18 \mathrm{~cm}$, предпосевную культивацию на глубину 6-8 см. В эксперименте использовали гибрид кукурузы $F_{1}$ Катерина СВ. Гибрид относится к раннеспелым (ФАО 170), холодостойкий, с хорошим начальным развитием. Посев семян провели сеялкой СВУ_8У на глубину 6 см, норма высева 25 кг/га. Предшественник - чистый пар. Применяли гербициды, действующие вещества которых указаны в таблице 1.

\section{Схема опыта}

Таблица 1

\begin{tabular}{|c|l|}
\hline $\begin{array}{c}\text { Номер } \\
\text { варианта }\end{array}$ & \multicolumn{1}{|c|}{ Действующее вещество гербицида } \\
\hline 0 & Контроль (без применения гербицида) \\
\hline 1 & Изоксафлютол + тиенкарбазон-метил + ципросульфамид \\
\hline 2 & Форамсульфурон + йодосульффурон-метил-натрия + изоксадифенэтил \\
\hline 3 & $\begin{array}{l}\text { Форамсульфурон + йодосульфурон-метил-натрий + тиенкарбазон-метил + ципро- } \\
\text { сульфрамид }\end{array}$ \\
\hline
\end{tabular}

Обработка посевов кукурузы гербицидами проведена в фазе развития 4-5-го листа культуры.

Почвенные образцы отбирали из слоев 0-10 и 10-20 см до обработки посевов гербицидами (фон), а также через 7 и 37 дней после обработки.

Основные химические показатели по характеристике почв получены при помощи общепринятых методов [5]. В почвенных пробах были определены: pH водной суспензии, содержание аммонийного азота - потенциометрически, щелочногидролизуемого азота $\left(\mathrm{N}_{щ г}\right)$ - по Корнфилду. Активность уреазы определяли по [6]. Статистическую обработку данных провели, используя пакет программ Excel.

Результаты исследования и их обсуждение. Легкогидролизуемая форма азота, являясь ближайшим резервом минерального питания растений, подвержена влиянию различных факторов. Хорошо известно о таких причинах, как гидротермические условия и обработка почвы. Информации о влиянии гербицидов на направленность трансформации органического азота практически нет. Известно, что попадая в почву, гербициды оказывают воздействие на микробиологические процессы, происходящие в ней. По различным данным, на непосредственное подавление сорной растительности расходуется от 1-2 до 10-40 \% от вносимого количества гербицида, остальная его часть вымывается в грунтовые воды или связывается с почвенным материалом, создавая значительные экологические проблемы [7]. Соединения, гидролизуемые щелочью, вовлекаются в превращения и могут сообщать о векторе трансформации, а значит информировать о степени воздействия исследуемого фактора. В почве анализируемых вариантов до использования гербицидов (фон) содержание щелочногидролизуемого азота в целом соответствовало высокой оценке по шкале обеспеченности сельскохозяйственных растений элементом, которую предложил [8]. Спустя неделю после применения, агрохимикаты закономерно повлияли на динамику изменений $\mathrm{N}_{щ г}$ (табл. 2). 
Содержание щелочногидролизуемого азота, мг/кг

\begin{tabular}{|l|c|c|c|c|c|c|}
\hline \multirow{2}{*}{ Вариант } & \multicolumn{9}{|c|}{ Срок } \\
\cline { 2 - 7 } & \multicolumn{2}{|c|}{$\begin{array}{c}\text { Фон - до обработки } \\
\text { гербицидами }\end{array}$} & \multicolumn{2}{|c|}{$\begin{array}{c}\text { После обработки - } \\
26 \text { июня }\end{array}$} & \multicolumn{2}{|c|}{$\begin{array}{c}\text { После обработки - } \\
\text { 31 июля }\end{array}$} \\
\cline { 2 - 7 } & $0-10 \mathrm{~cm}$ & $10-20 \mathrm{~cm}$ & $0-10 \mathrm{~cm}$ & $10-20 \mathrm{~cm}$ & $0-10 \mathrm{~cm}$ & $10-20 \mathrm{~cm}$ \\
\hline Контроль & 203 & 194 & $193^{*}$ & 187 & 203 & 192 \\
\hline Вариант 1 & 215 & 224 & $243^{*}$ & 242 & 250 & 222 \\
\hline Вариант 2 & 233 & 264 & 229 & 229 & 225 & 219 \\
\hline Вариант 3 & 233 & 264 & $205^{*}$ & $196^{*}$ & 199 & 190 \\
\hline НСР $_{05}$ & 13 & 33 & 20 & 32 & 23 & 38 \\
\hline
\end{tabular}

* Здесь и далее: достоверные различия в динамике.

На варианте опыта 1 отмечалось достоверное повышение легкогидролизуемых веществ, а в почве на варианте опыта 2 их содержание значимо снижалось, тогда как в почве контрольного варианта отмечено существенное пониже-

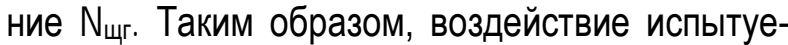
мых гербицидов не выявило закономерных изменений в превращениях легкогидролизуемых соединений азота на данном этапе наблюдений.

Важнейшим агентом в трансформации азотсодержащих соединений в почве являются фрерменты азотного цикла. Так как «слабым» местом почв Сибирского региона является низкая обеспеченность минеральным азотом в весенний период, то «наложение» на это время гербицидной нагрузки, вероятно, обусловливает дефицит элемента.

Воздействие, оказываемое гербицидами на почвенные биохимические процессы, зависит, прежде всего, от их химического состава. Интересно отметить, что по химическому составу изучаемые гербициды являются органическими азотсодержащими соединениями. Одним из компонентов применяемых в опыте химикатов были азотсодержащие антидоты. Так, в составе гербицидов на вариантах опыта 1 и 3 использо- вался ципросульфрамид. Таким образом, адсорбируясь почвенными элементарными частицами, гербициды и их компоненты могут обнаруживать, возможно, как стимулирующий, так и ингибирующий эфффект. Экспериментами установлен существенный ингибирующий эфрфект уреазы такими органическими соединениями, как алифатические амины, дегидрофенолы и хиноны. Данные соединения входят в структуру исследуемых нами гербицидов.

Представленные в таблице 3 материалы свидетельствует о возможном ингибирующем влиянии гербицидов на варианте опыта 1 и 2 на почвенную уреазу. Так, в предшествующий обработке гербицидами период ее активность была существенно выше в почве делянок данных вариантов. Через неделю после опрыскивания обнаруживалось значимое снижение активности. Входящий в состав гербицида на варианте опыта 2 антидот изоксадифен-этил не оказывал аналогичного ингибирующего влияния на интенсивность гидролиза мочевины. В целом результаты активности уреазы всех вариантов опыта показали слабую обеспеченность почвы этим ферментом.

\section{Активность уреазы чернозема выщелоченного (мг N-NH $4 / 10$ г/24 ч)}

Таблица 3

\begin{tabular}{|l|c|c|c|c|c|c|}
\hline \multirow{3}{*}{ Вариант } & \multicolumn{9}{|c|}{ Срок } \\
\cline { 2 - 7 } & $\begin{array}{c}\text { Фон - до обработки } \\
\text { гербицидами }\end{array}$ & $\begin{array}{c}\text { После обработки - } \\
26 \text { июня }\end{array}$ & $\begin{array}{c}\text { После обработки - 31 } \\
\text { июля }\end{array}$ \\
\cline { 2 - 7 } & $0-10$ см & $10-20 \mathrm{~cm}$ & $0-10 \mathrm{~cm}$ & $10-20 \mathrm{~cm}$ & $0-10 \mathrm{~cm}$ & $10-20 \mathrm{~cm}$ \\
\hline 1 & 2 & 3 & 4 & 5 & 6 & 7 \\
\hline Контроль & 2,49 & 1,01 & 1,63 & 2,73 & 3,77 & 4,44 \\
\hline Вариант 1 & 9,05 & 5,33 & $1,57^{\star}$ & $2,45^{\star}$ & 3,12 & 1,73 \\
\hline
\end{tabular}


Окончание табл. 3

\begin{tabular}{|l|c|c|c|c|c|c|}
\hline \multicolumn{1}{|c|}{1} & 2 & 3 & 4 & 5 & 6 & 7 \\
\hline Вариант 2 & 9,65 & 10,77 & $2,25^{\star}$ & $6,16^{*}$ & 1,00 & 0,50 \\
\hline Вариант 3 & 2,93 & 2,85 & 1,64 & 1,22 & 3,55 & 4,58 \\
\hline $\mathrm{HCP}_{05}$ & 2,45 & 3,00 & $\mathrm{~F}_{\Phi}<\mathrm{F}_{\mathrm{T}}$ & 1,96 & 1,56 & 1,33 \\
\hline
\end{tabular}

Исследованиями установлено, что в агроэкосистемах быстрое нарастание активности уреазы свидетельствует о способности накопления в почве аммиачного азота. Нашими наблюдениями указанная зависимость не подтвердилась. Снижение активности уреазы сопровождалось достоверным нарастанием содержания аммонийного азота. Это указывает на то, что данная форма азота стала результатом деятельности других процессов, переводящих азотсодержащие органические соединения в аммиачную формм.

Полученные данные указывают на очень низкую обеспеченность аммиачным азотом почвы всех вариантов (табл. 4). Однако причины, обусловившие такой уровень, могли быть различные, в том числе использование минераль- ного азота растениями в период интенсивного нарастания вегетативной массы. Минимальная концентрация аммиачного азота обнаруживалась в почве варианта, обработанного гербицидом на варианте опыта 3, что коррелировало с пониженной активностью уреазы, особенно в слое 10-20 см. Напротив, предельные значения $\mathrm{N}-\mathrm{NH}_{4}$ диагностировались в почве, где использовался гербицид с действующими веществами форамсульфрурон + йодосульфурон-метилнатрия + изоксадифренэтила (вариант 2). Причем, этот максимум был также сопряжен с повышенной уреазной активностью.

Данные по урожайности кукурузы показывают достоверное увеличение зеленой массы данной культуры при использовании гербицидов (табл. 5).

\section{Содержание аммонийного азота, мг/кг}

Таблица 4

\begin{tabular}{|c|c|c|c|c|c|c|}
\hline \multirow{3}{*}{ Вариант } & \multicolumn{6}{|c|}{ Срок } \\
\hline & \multicolumn{2}{|c|}{$\begin{array}{c}\text { Фон - до обработки } \\
\text { гербицидами }\end{array}$} & \multicolumn{2}{|c|}{$\begin{array}{c}\text { После обработки - } \\
26 \text { июня }\end{array}$} & \multicolumn{2}{|c|}{$\begin{array}{c}\text { После обработки - } \\
31 \text { июля }\end{array}$} \\
\hline & $0-10 \mathrm{~cm}$ & $10-20 \mathrm{~cm}$ & $0-10 \mathrm{~cm}$ & $10-20 \mathrm{~cm}$ & $0-10 \mathrm{~cm}$ & $10-20 \mathrm{~cm}$ \\
\hline Контроль & 1,64 & 1,34 & $3,54^{*}$ & $2,90^{*}$ & 4,37 & 2,92 \\
\hline Вариант 1 & 1,80 & 1,99 & $3,51^{*}$ & $3,14^{*}$ & 5,25 & 3,83 \\
\hline Вариант 2 & 2,25 & 1,87 & $3,84^{*}$ & $3,65^{*}$ & 3,69 & 3,41 \\
\hline Вариант 3 & 2,44 & 1,98 & 2,72 & $2,48^{*}$ & 3,18 & 2,61 \\
\hline $\mathrm{HCP}_{05}$ & $\mathrm{~F}_{\phi}<\mathrm{F}_{\mathrm{T}}$ & $\mathrm{F}_{\Phi}<\mathrm{F}_{\mathrm{T}}$ & 0,72 & 0,60 & 1,50 & 0,71 \\
\hline
\end{tabular}

\section{Влияние гербицидов на урожайность зеленой массы кукурузы}

\begin{tabular}{|c|c|c|c|c|}
\hline \multirow{3}{*}{ Вариант } & \multicolumn{3}{|c|}{ Урожайность зеленой массы } & \multirow{3}{*}{ Спелость зерна } \\
\hline & \multirow{2}{*}{ ц/га } & \multicolumn{2}{|c|}{ 土 к контролю } & \\
\hline & & ц/га & $\%$ & \\
\hline Контроль & 206,5 & - & - & \multirow{5}{*}{ Молочная - молочно-восковая } \\
\hline Вариант 1 & 251,4 & $+44,9$ & $+21,7$ & \\
\hline Вариант 2 & 343,4 & $+136,9$ & $+66,3$ & \\
\hline Вариант 3 & 316,8 & $+110,3$ & $+53,5$ & \\
\hline $\mathrm{HCP}_{05}$ & 34,8 & & & \\
\hline
\end{tabular}


Биологической особенностью кукурузы является ее сравнительно высокая засухоустойчивость. Однако длительное отсутствие осадков в фазе всходов и от 15-го листа до спелости привело к снижению продуктивности культуры. Растения контрольного варианта сформировали лишь 206,5 ц/га зеленой массы.

Использование гербицидов оказало существенное влияние на формирование зеленой мас- сы, обеспечив повышение продуктивности по отношению к контролю от 21,7 до $66,3 \%$. На формирование общего веса зеленой массы кукурузы оказывали влияние высота растений, а также количество сфрормировавшихся початков и их вес.

Применение гербицидов также обеспечило повышение биометрических параметров растений (табл. 6).

\section{Морфометрические показатели гибридов кукурузы}

Таблица 6

\begin{tabular}{|l|c|c|c|}
\hline \multicolumn{1}{|c|}{ Вариант } & $\begin{array}{c}\text { Высота } \\
\text { растений, см }\end{array}$ & $\begin{array}{c}\text { Среднее кол-во початков } \\
\text { на 1 растении, шт. }\end{array}$ & $\begin{array}{c}\text { Средний вес } \\
\text { початка, кг }\end{array}$ \\
\hline Контроль & 183,9 & 1,0 & 0,126 \\
\hline Вариант 1 & 216,3 & 1,2 & 0,136 \\
\hline Вариант 2 & 234,4 & 1,0 & 0,168 \\
\hline Вариант 3 & 232,2 & 1,2 & 0,148 \\
\hline HСР $_{05}$ & 15,6 & 0,1 & 0,015 \\
\hline
\end{tabular}

Высота растений на контрольном варианте в среднем составила 184 см. Применение гербицидов оказало значительное влияние на рост растений кукурузы, способствуя повышению морфометрических показателей.

Наличие низкой конкурентной нагрузки со стороны сорной растительности за потребление питательных веществ и влаги на начальных, наиболее уязвимых фазах развития кукурузы на вариантах опыта 2 и 3, повысило темпы поступательного развития стебля растений.

Высота растений на делянках, обработанных гербицидами на вариантах опыта 2 и 3, находилась на одном уровне, но на 27,5 и 26,3 \% превосходила контрольный показатель. Высота растений на участке варианта 1 превышала контроль на 32,4 см, что составляет 17,6\%. Практически каждое растение кукурузы сформировало по 1 полноценному початку. Химическая защита растений от сорного компонента обнаружила значительное нарастание веса початка: на контроле его средний вес составил 0,126 кг. При применении гербицидов вес початков изменялся от 0,136 до 0,168 кг.

Выводы. В целом результаты опыта свидетельствуют о двойственном влиянии исследуемых гербицидов на превращение соединений азота в почве под растениями кукурузы. Низкая активность уреазы в почве вариантов опыта свидетельствует о слабой обеспеченности почвы исходным органическим субстратом. С дру- гой стороны, установлено, что воздействие на активность фермента может оказывать насыщенность почвы гербицидами предшествующих лет использования. Также воздействие испытуемых гербицидов не выявило закономерных изменений в превращениях легкогидролизуемых соединений азота. Исследования показали, что в условиях Сухобузимского района Красноярской лесостепи можно выращивать кукурузу на силос с початками восковой спелости. Предлагаемая система защиты растений кукурузы от сегетальной растительности обеспечивает высокую хозяйственную эффективность.

\section{Литература}

1. Брылев С.В., Бопn В.Л., Литвинова В.С. и др. Состояние и перспективы выращивания кукурузы в условиях Красноярского края // Кукуруза и сорго. - 2018. - № 4. - С. 32-35.

2. Мамиев Д.М., Абаев А.А., Оказова З.П. Влияние удобрений и гербицидов на биологическую активность почвы в горной зоне // Успехи современного естествознания. 2016. - № 7. - С. 81-85.

3. Белоусова Е.Н., Белоусов А.А. Трансформация азотсодержащих соединений чернозема выщелоченного в условиях минимизации обработки // Вестн. КрасГАУ. - 2017. № 5. - C. 149-156. 
4. Белоусов А.А., Белоусова Е.Н. Влияние структурного состава почвы и агрохимикатов на содержание углерода микробной биомассы // Вестн. Бурят. гос. с.-Х. акад. им. В.Р. Филиппова. - 2013. - № 2. - С. 25-31.

5. Аринушкина Е.В. Руководство по химическому анализу почв. - М.: Изд-во МГУ, 1970. $487 \mathrm{c}$.

6. Хазиев Ф.Х. Ферментативная активность почв. - М.: Наука, 1976. - 180 с.

7. Анисимова М.А. Детоксицирующая способность почв и выделенных из них гуминовых кислот по отношению к гербицидам: дис. ... канд. биол. наук: 03.00.27. - М., 1997. - 127 с.

8. Шконде Э.И., Королева И.Е. О природе и подвижности почвенного азота // Агрохимия. - 1964. - № 10. - С. 17-35.

\section{Literatura}

1. Brylev S.V., Bopp V.L., Litvinova V.S. i dr. Sostoyanie i perspektivy vyrashchivaniya kukuruzy v usloviyah Krasnoyarskogo kraya /I Kukuruza i sorgo. - 2018. - № 4. - S. 32-35.

2. Mamiev D.M., Abaev A.A., Okazova Z.P. Vliyanie udobrenij i gerbicidov na biologicheskuyu aktivnost' pochvy $v$ gornoj zone // Uspekhi sovremennogo estestvoznaniya. - 2016. - № 7. - S. 81-85.

3. Belousova E.N., Belousov A.A. Transformaciya azotsoderzhashchih soedinenij chernozema vyshchelochennogo $\mathrm{v}$ usloviyah minimizacii obrabotki // Vestn. KrasGAU. - 2017. № 5. - S. 149-156.

4. Belousov A.A., Belousova E.N. Vliyanie strukturnogo sostava pochvy i agrohimikatov na soderzhanie ugleroda mikrobnoj biomassy // Vestn. Buryat. gos. s.-h. akad. im. V.R. Filippova. - 2013. - № 2. - S. 25-31.

5. Arinushkina E.V. Rukovodstvo po himicheskomu analizu pochv. - M.: Izd-vo MGU, 1970. - $487 \mathrm{~s}$.

6. Haziev F.H. Fermentativnaya aktivnost' pochv. - M.: Nauka, 1976. - $180 \mathrm{~s}$.

7. Anisimova M.A. Detoksiciruyushchaya sposobnost' pochv i vydelennyh iz nih guminovyh kislot po otnosheniyu $\mathrm{k}$ gerbicidam: dis. ... kand. biol. nauk: 03.00.27. - M., 1997. $127 \mathrm{~s}$.

8. SHkonde E.I., Koroleva I.E. O prirode i podvizhnosti pochvennogo azota // Agrohimiya. 1964. - № 10. - S. 17-35. 